\title{
Vibration isolation measures due to the high sensitive linear accelerator at the Paul Scherrer Institute
}

\author{
Peter Trombik ${ }^{1, a}$, Pascal Fleischer ${ }^{1}$ and Michalis F. Vassiliou ${ }^{1}$ \\ ${ }^{1}$ Trombik Ingenieure AG, Zurich Switzerland
}

\begin{abstract}
The new 735m long linear accelerator "SwissFEL" at the Paul Scherrer Institute (PSI) in Würenlingen is extremely sensitive against vibrations coming from surrounding equipment (pumps, ventilators, transformers, etc.). The manufacturer's vibration limit for this linear accelerator is $0.1 \mu \mathrm{m}$ displacement amplitude. Therefore, all vibration sources must strictly be isolated to the highest-possible degree from the rest of the structure. This paper discusses the vibration situation in general for this unique construction (ground vibrations, vibration propagations / structural amplifications, vibration limits, etc.) and as a case study the isolation of a pump located in the building. Steel springs were used and it was achieved to reduce the vibration transmitted to the floor by more than $99 \%$, to a level where the coherent component of the motion recorded on the floor next to the linear accelerator is nonmeasurable / below the ground motions. The measurements were found to be in good accordance with the FEM model used.
\end{abstract}

\section{Introduction}

The Swiss Free Electron Laser (FEL) is located in the Paul Scherrer Institute (PSI) in Würenlingen. Electron beams are accelerated through linear accelerators, located in a concrete tunnel of $735 \mathrm{~m}$ length. Afterwards they are sent into an array of alternatively poled magnets which deflect them into a wavy path. This curved motion induces the electrons to radiate away energy in form of $\mathrm{X}$-rays. The X-rays are used for several scientific experiments (e.g. to better understand catalytic materials with applications in the chemical industry, to improve imaging techniques to unravel the structure of biomolecules vital for the development of smarter drugs and to gain new insights into technologically appealing but as yet poorly understood materials) [1].

In order for the FEL to function properly, very strict structural displacement values are allowed, both under static and under dynamic loading. The dynamic loading comes both from external (like a nearby factory) and internal sources, like machines necessary for the function of the FEL. The allowable displacements are very strict and the design and construction of the FEL was done with great care in order not to exceed them. Their exceedance would lead to the malfunction of FEL. Therefore some sources of vibration had to be elastically supported and decoupled from the building.

\section{Vibration Limits and Conceptual Measures}

The vibration limits are defined in [2] and must be fulfilled in all the area of the facility, under simultaneous function of all the devices. They should be measured on the top of the floor plate [2]. The maximum allowed displacement under dynamic loading is $0.1 \mu \mathrm{m}=10^{-7} \mathrm{~m}$, in the frequency range between 1 and $100 \mathrm{~Hz}$.

Moreover some extra conceptual measures are demanded by the PSI.

\subsection{Machines and appliances}

In general, all machine and appliances that are potential sources of vibration should be isolated from the main structure. To this end elastic supports could be used.

Machines and appliances with rotating parts should have an operation frequency higher than 1400rpm $(=23 \mathrm{~Hz})$.

Machines that are expected to be started or stopped during the regular function of the SwissFEL should have enough damping to avoid resonance with the building during their start-up and close-down. The same guideline applies to back-up machines and appliances that are expected to be started in case of failure of the normal ones.

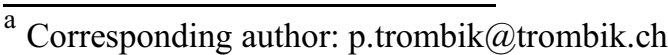




\subsection{Pumps}

All pumps with power larger than $5 \mathrm{~kW}$ (Figure 1) must be elastically decoupled from the rest of the structure. To this end steel spring elements were used. The isolated system should have low eigenfrequencies, so that a high degree of isolation is achieved (low tuned system). A minimum degree of isolation equal to $95 \%$ is demanded. For obvious reasons, no rigid connection between the concrete base and the rest of the structure is allowed. As with all machines in SwissFEL, in case the pumps are expected to start-up or shut-down during regular operation of the facility, enough damping should be provided so that the vibration amplitudes stay low when the machine passes through the system resonance frequencies.

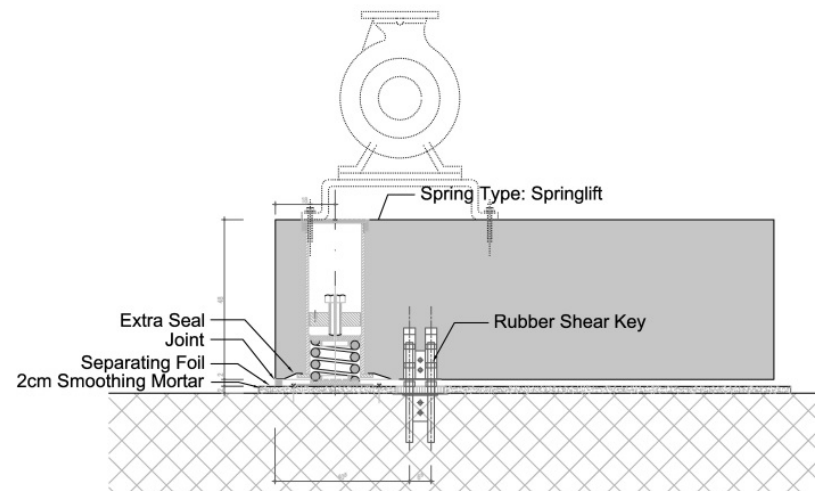

Figure 1. Concrete foundation supported by special springs ("Springlift"), shear keys for horizontal stability (seismic loads)

\subsection{Pipes}

All pipes with fluids must be decoupled from vibration sources (pumps, Monoblocks, Ventilators, Compressors etc) before their first support. There should be used either one $3 \mathrm{~d}$ flexible joint or two $2 \mathrm{~d}$ joints in perpendicular directions. The joints should have the largest possible flexibility so that the whole system is low tuned. After the flexible joint, the pipe should be rigidly connected to the rest of the structure and should have a natural frequency larger than $12 \mathrm{~Hz}$ [3].

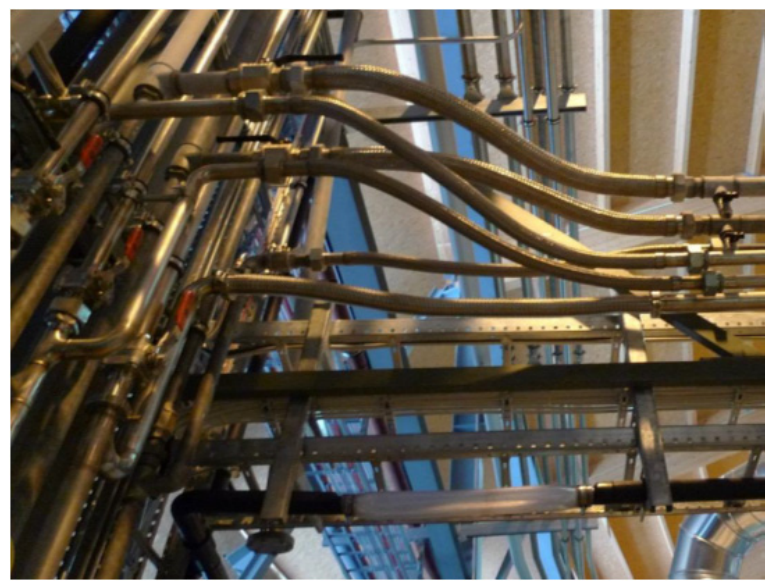

Figure 2. Pipes with flexible joints.

\subsection{Ventilation Appliances / Monoblocks}

All ventilation appliances [3] must be supported similarly to the pumps (Section 2.2). For a flow less than $20^{\prime} 000 \mathrm{~m}^{3} / \mathrm{h}$ they can be generally supported by an elastic pad on a concrete base. In any case connection plates are necessary so that the vertical load is distributed on the elastic bearing. Again, a low frequency is targeted so that a minimum isolation degree of $95 \%$ is achieved.

Monoblocks that are hanging from the ceiling must be isolated through elastic supports. There must be no rigid connection via ventilation pipes, tubes, supports or cable channels.

Ventilation appliances and monoblocks with flow larger than $20^{\prime} 000 \mathrm{~m}^{3} / \mathrm{h}$ should be connected to a concrete block, and mechanical springs (like in section 2.2) should be used.

Trombik Ing. AG measured the vibrations caused by a Monoblock supported by Elastomeric pads on site (Figure 3). It was found that the vibration amplitudes were below the limits set by PSI.

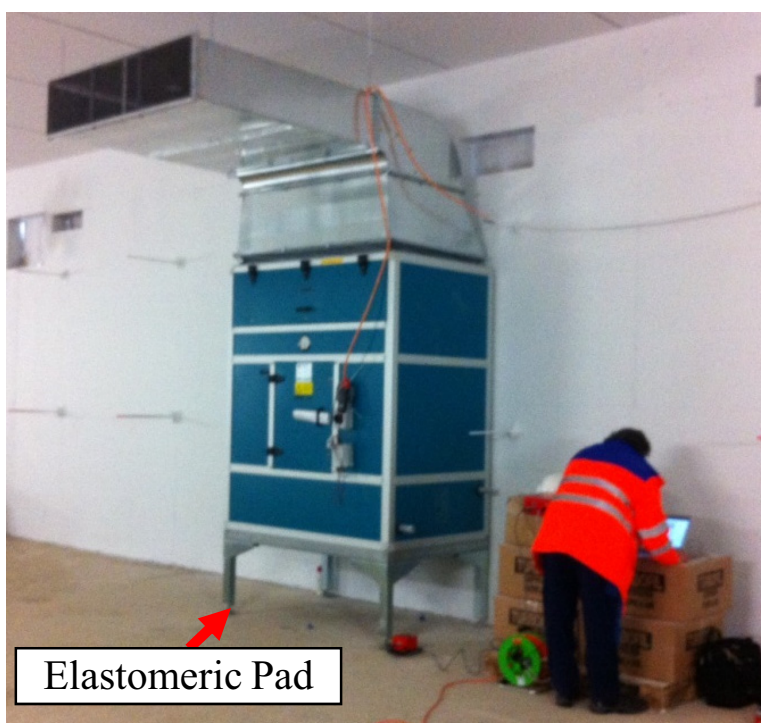

Figure 3. PSI Monoblock supported by an elastomeric pad.

\subsection{Ventilation channels}

All ventilation channels [3] must be flexibly connected to the vibration source (Monoblocks, Ventilators, etc.) before their first rigid support. After the flexible support, the ventilation channels should be firmly connected to the structure.

\subsection{Transformers}

Transformers (Figure 4) and electrical components [3] that cause vibrations should be supported similarly to pumps (section 2.2) or monoblocks (section 2.4). If elastomeric bearings are used, they should be resistant to oil. Rigid connections like stiff copper conductions and cooling pipes are not allowed

A typical non-isolated transformer was measured in PSI. The vibrations caused by it were found to be larger than the allowable limits. Therefore it was suggested that 
the transformers be supported by elastomeric parts. This would typically result in basic eigenfrequencies on the order of $10-15 \mathrm{~Hz}$. Considering that the excitation frequency is $100 \mathrm{~Hz}$, the isolation factor achieved would be $43 \%-99 \%$.

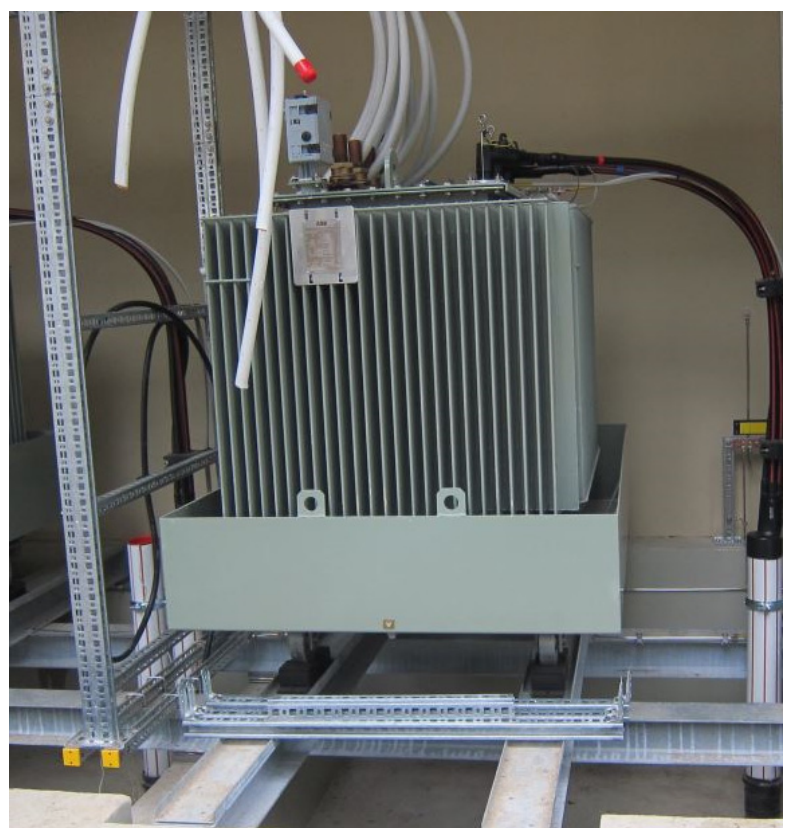

Figure 4. PSI Transformer supported by elastomeric pads.

\subsection{Crane runways}

The crane runways [3] should be elastically decoupled from the main structure.

\subsection{Separation with gaps}

The vertical gaps (Figure 5) [3] should have a minimum width of $30 \mathrm{~mm}$. They should be filled with soft mineral wool or with a soft elastomeric material. In no case should the gap be filled with foam.

The gap should be covered with a profile able to take loading and should be protected from dirt.

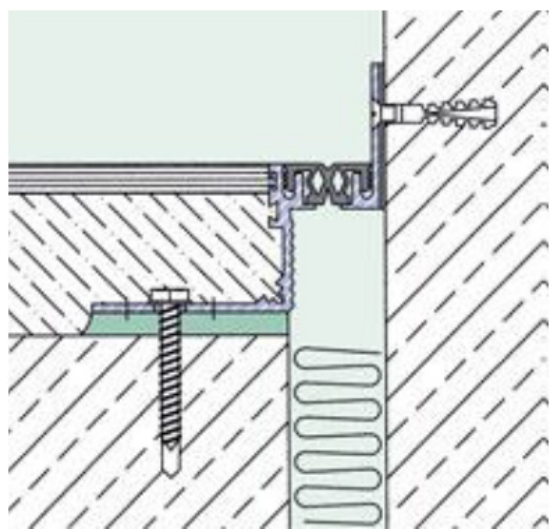

Figure 5. Separation gap.

\section{Case Study: Pump Isolation}

Trombik Ing. AG, which specializes in the development, construction and design of machine foundations and, if applicable, in their supporting steel spring elements, was asked to provide design help for all above mentioned isolation systems. Governing in the present context are the ventilators / Monoblocks, the Transformers and the Pumps. Considering the importance of these vibration sources, the design and execution of one installation of each type was advanced and tested out by measurements, so the results of these preliminary studies could be taken into consideration for the final design of all corresponding equipment. In the following, the case study of pumps Nr. PO 30 and PO 31 is presented. The pumps are supported by a spring mounted concrete base, i.e. the base is fully isolated from the rest of the structure.

\subsection{System of TROMBIK Spring Mounted Pedstal}

The „Springlift“ system was used (Figure 1). The system consists of steel springs that are placed in specially designed nests inside the concrete foundation (Figure 6). Steel cases that contain the springs are placed in the formwork before the concrete is poured (Figure 7). Thanks to the special construction of the springs, they are used as jacks and the foundation is mechanically lifted by $2 \mathrm{~cm}$ after the concrete curing (Figure 8 ). This procedure takes place from the top side of the foundation without the use of any extra jacks. By adjusting the spring deformation, it is possible to redistribute the force that each spring takes. This facilitates the optimal distribution of the total (machine plus foundation) weight. No special jacks are needed for the erection.

In the horizontal direction, the foundation is supported by shear keys (Figure 1) that are flexible for small amplitude vibration but lock and become stiffer for large amplitude vibration, thus providing the necessary strength in case of an earthquake.

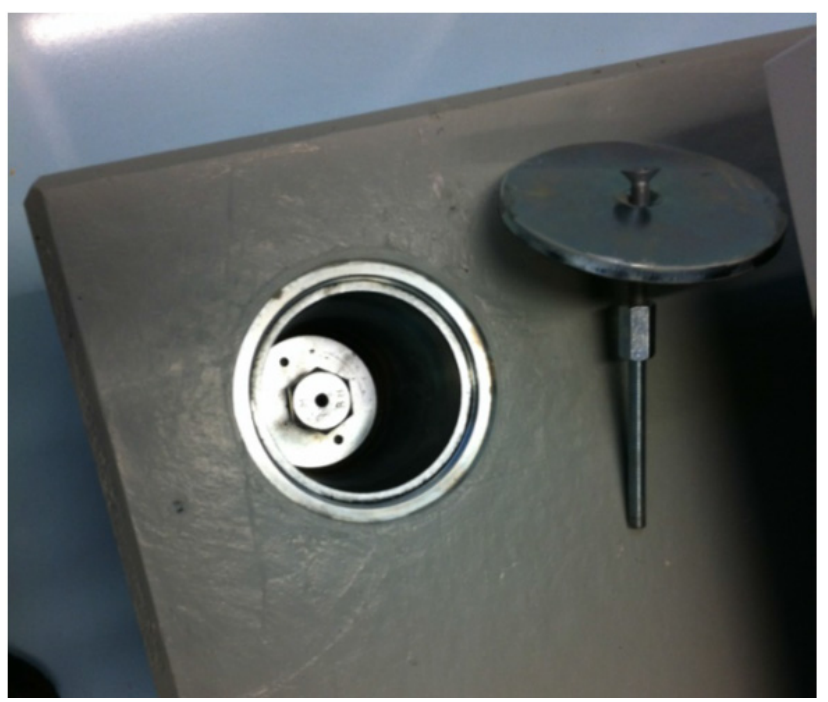

Figure 6. Steel cases where the springs are nested. 


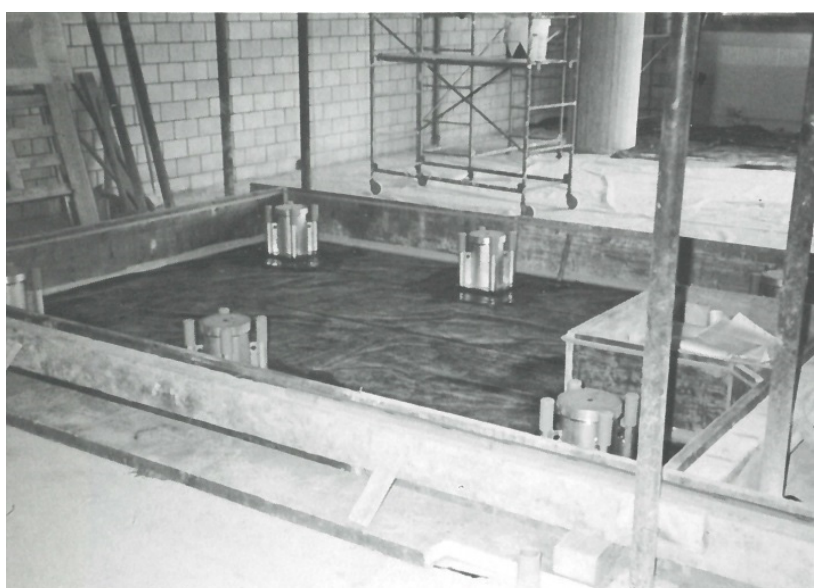

Figure 7. Formwork with springs.

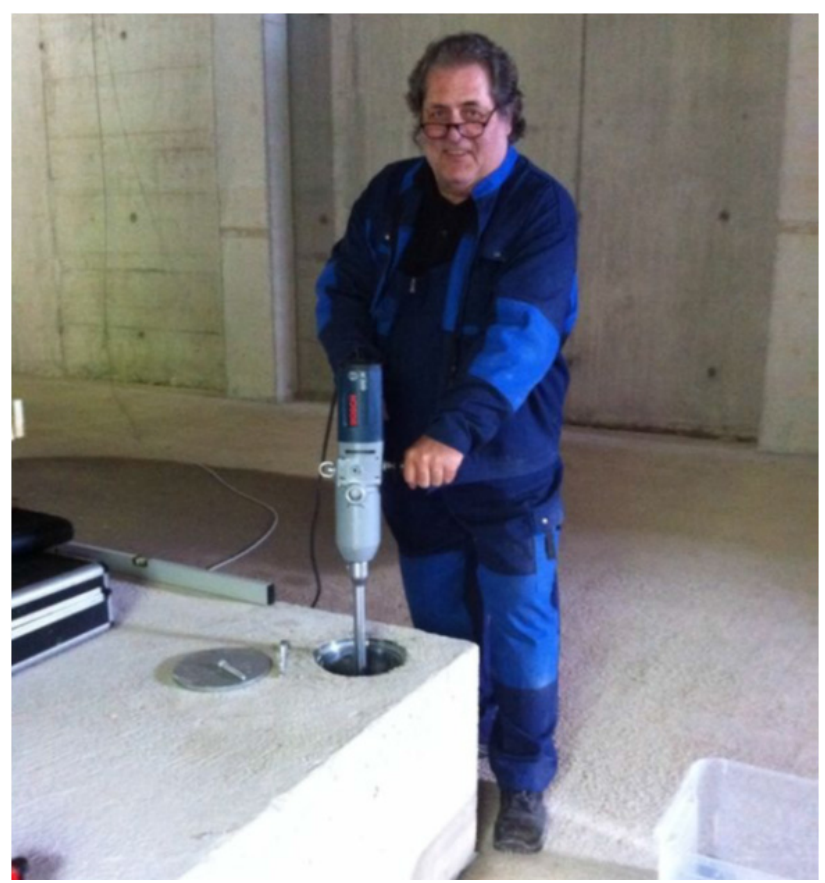

Figure 8. Activation of the spring elements / of the spring mounted foundation.

The above described spring system presents the following advantages:

1) It is easily constructed. The concrete foundation is constructed directly over the existing plate and then lifted using the spring elements.

2) It can be very flexible, thus leading to very low isolation frequencies

3) The springs are easily accessible for inspection.

4) There is no creep deformation.

5) It is easy to take possible support displacements

6) Their stiffness in all directions is well determined

7) Good fire resistance and long term behavior

\subsection{Maximum allowed vibrations on Floor 1}

The maximum allowed vibration allowed by the PSI are given in Figure 9.

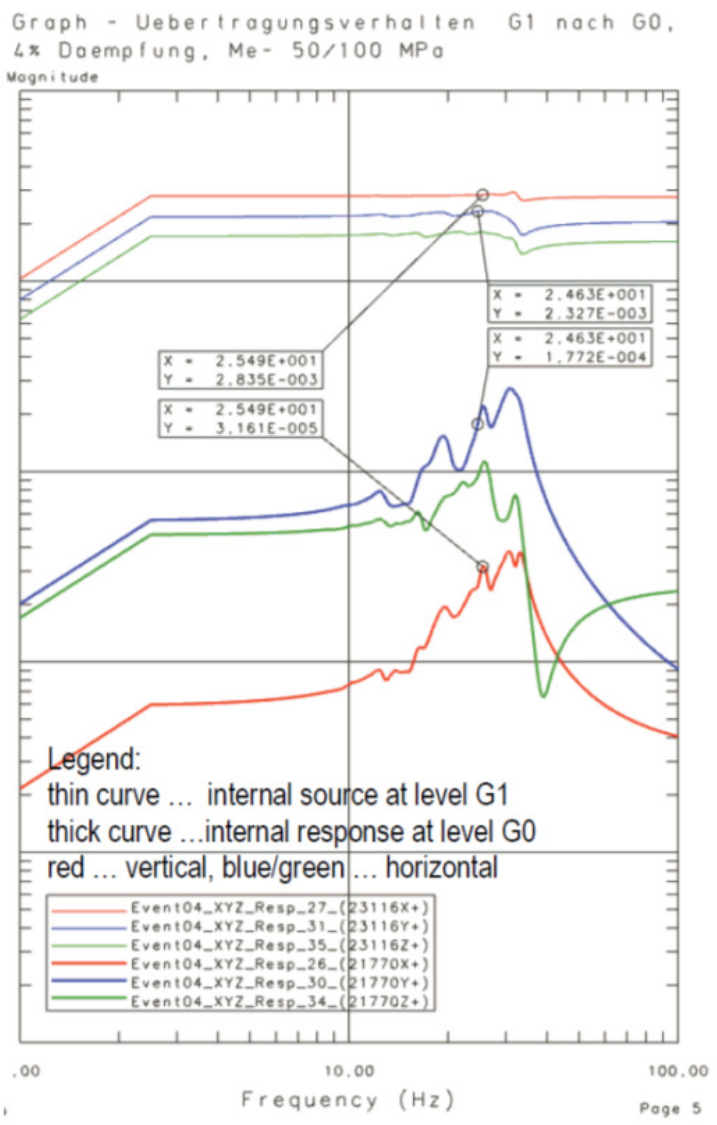

Figure 9. Vibration limits.

\subsection{Spring Design/Numerical modeling}

When the measurements took place, the pumps were not yet placed on the concrete bases. Therefore, it was chosen to measure a test base using an electrodynamic shaker. Since the absence of the pump makes the system lighter, softer springs were used. The tested configuration simulates the final model. In the final configuration, stiffer springs were used.

The test foundation was modeled with STARDYNE FEM software. As mentioned before, softer springs were used in order to compensate for the lack of the pump mass. The springs were modeled with link elements with appropriate stiffness to simulate the vertical stiffness of the steel springs and the horizontal stiffness of the steel springs plus the horizontal stiffness of the rubber shear keys.

The computed eigenfrequencies and modes are given in Figure 10.

\subsection{Measurement configuration}

\subsubsection{Measurement and excitation devices}

The measurements were performed using the high precision devices MR2002 (Figure 11) by SYSCOM. The most important information is given in Table 1 . The specifications of the electrodynamic shaker are given in Table 2. Figure 12 shows the shaker. 

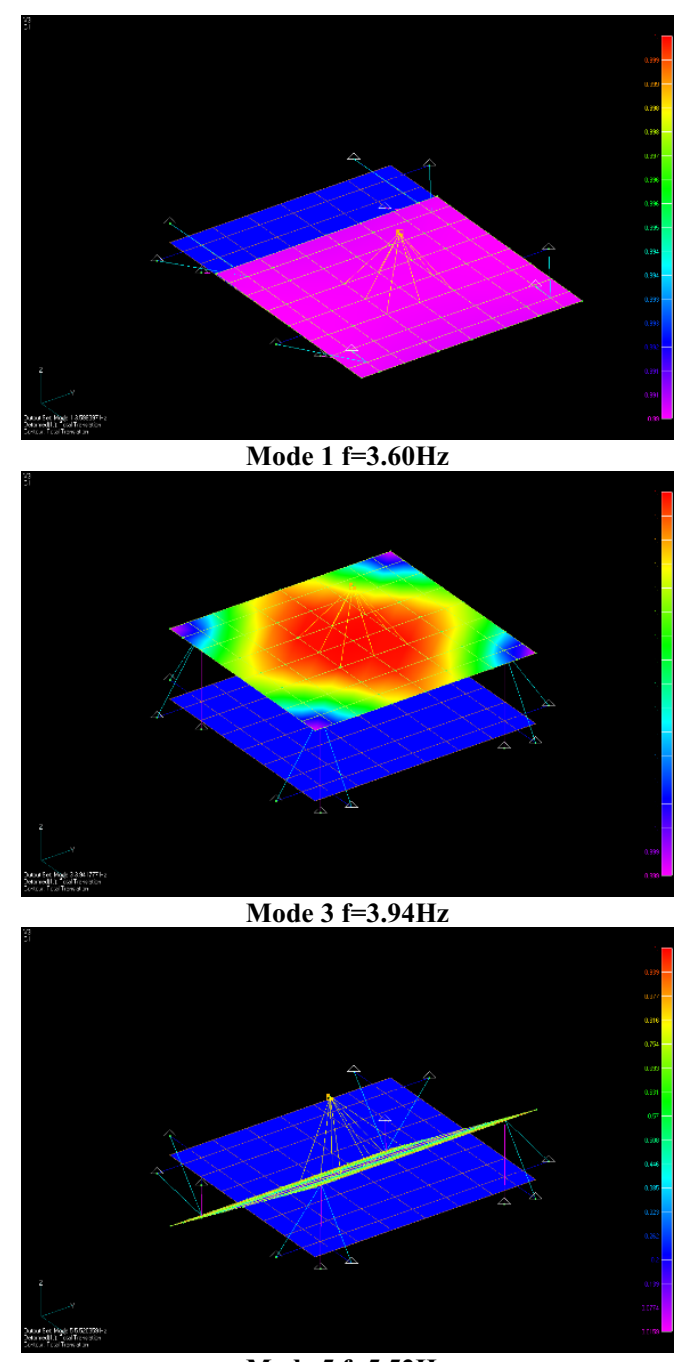

Mode $5 \mathrm{f}=5.52 \mathrm{~Hz}$

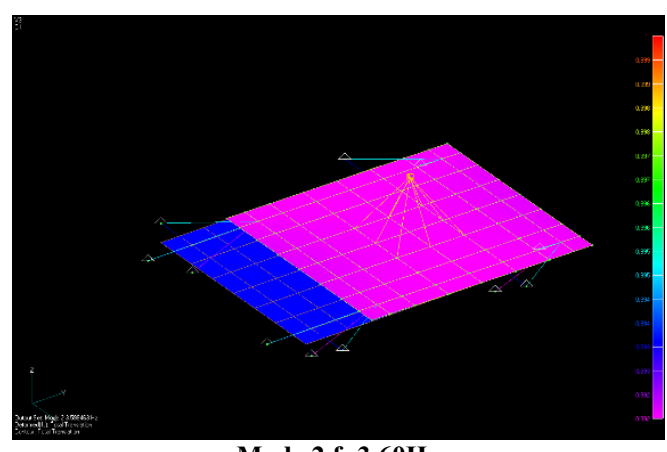

Mode $2 \mathrm{f}=3.60 \mathrm{~Hz}$

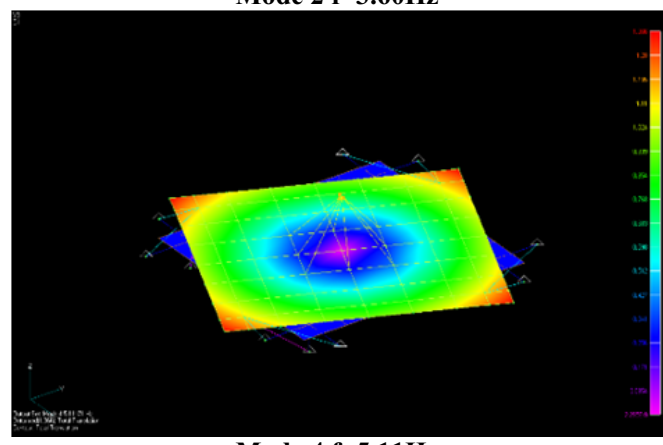

Mode $4 \mathrm{f}=5.11 \mathrm{~Hz}$

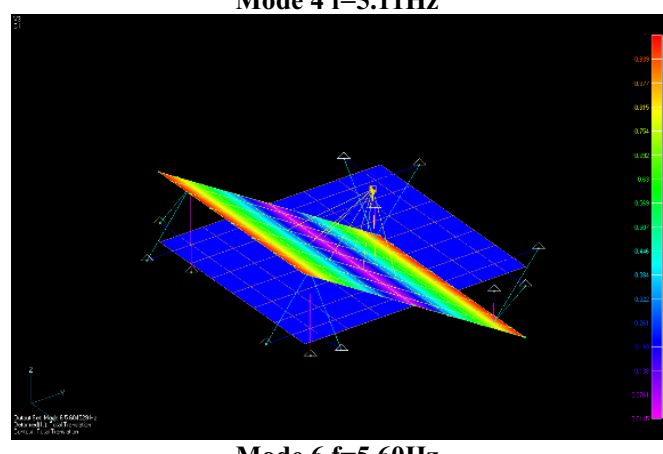

Mode $6 \mathrm{f}=5.60 \mathrm{~Hz}$

Figure 10. Computed mode shapes and eigenfrequencies.

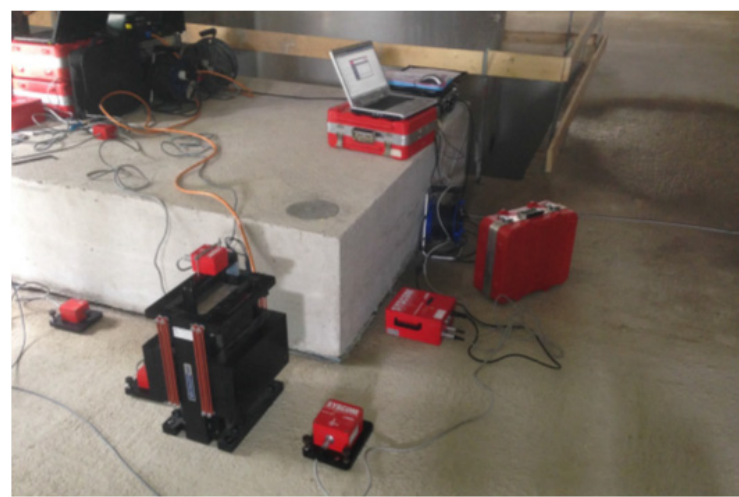

Figure 11. Concrete base with measuring equipment.

Table 1. Sensor Specifications

\begin{tabular}{|l|l|}
\hline Sensor & Uniaxial velocity sensor (Geophone) \\
\hline $\begin{array}{l}\text { Sampling } \\
\text { Frequency }\end{array}$ & 400 measurements per second \\
\hline Frequency & $1-160 \mathrm{~Hz}$ \\
\hline Amplitude & $0.0000035-100 \mathrm{~mm} / \mathrm{s}$ \\
\hline
\end{tabular}

Table 2. Shaker Specifications

\begin{tabular}{|c|c|}
\hline Model & APS 400 \\
\hline Max Force Sine Peak & $445 \mathrm{~N}(100 \mathrm{lb})$ \\
\hline Max. Velocity Sine Peak & $1,000 \mathrm{~mm} / \mathrm{s}$ (39 inch/s) \\
\hline Max. Stroke & $158 \mathrm{~mm}$ (6.25 inch) \\
\hline Frequency Range & DC $\ldots 200 \mathrm{~Hz}$ \\
\hline Operation & horizontal or vertical \\
\hline Armature Weight & $28 \mathrm{~kg}(6.2 \mathrm{lb})$ \\
\hline Max. Overhung Load at Armature Attachment Point & $9.0 \mathrm{~kg}(20 \mathrm{lb})$ \\
\hline Impedance & 1.60 \\
\hline Total Shaker Weight & $73.0 \mathrm{~kg}(161 \mathrm{lb})$ \\
\hline Shipping Weight & $86.0 \mathrm{~kg}$ (190 lb) \\
\hline Overall Dimension $\mathrm{L} \times \mathrm{W} \times \mathrm{H}$ & $\begin{array}{l}526 \times 314 \times 178 \mathrm{~mm} \\
(20.7 \times 124 \times 7.0 \mathrm{inch})\end{array}$ \\
\hline Operating Temperature & $5 \ldots 40$ degrees $C$ \\
\hline Storage Temperature & $-25 \ldots 55$ degrees $C$ \\
\hline
\end{tabular}

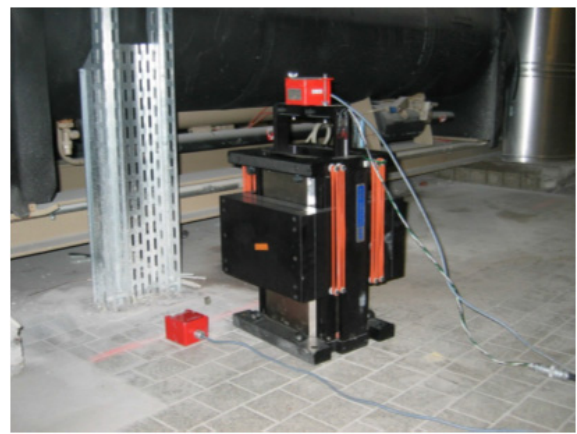

Figure 12. Electrodynamic shaker. 


\subsubsection{Shaker and sensor positions}

Measurements were taken in different positions both at the floor where the pump is situated (Floor 1) and at the floor below (Floor 0). Two sets of measurements were performed. First three uniaxial devices were used to measure the force of the shaker and the transfer spectrum (both the horizontal and the vertical). Then a separate triaxial sensor was used to measure the $3 \mathrm{~d}$ motion of the concrete base and the floor. Figure 13 shows the measurement configuration for vertical and horizontal excitation.
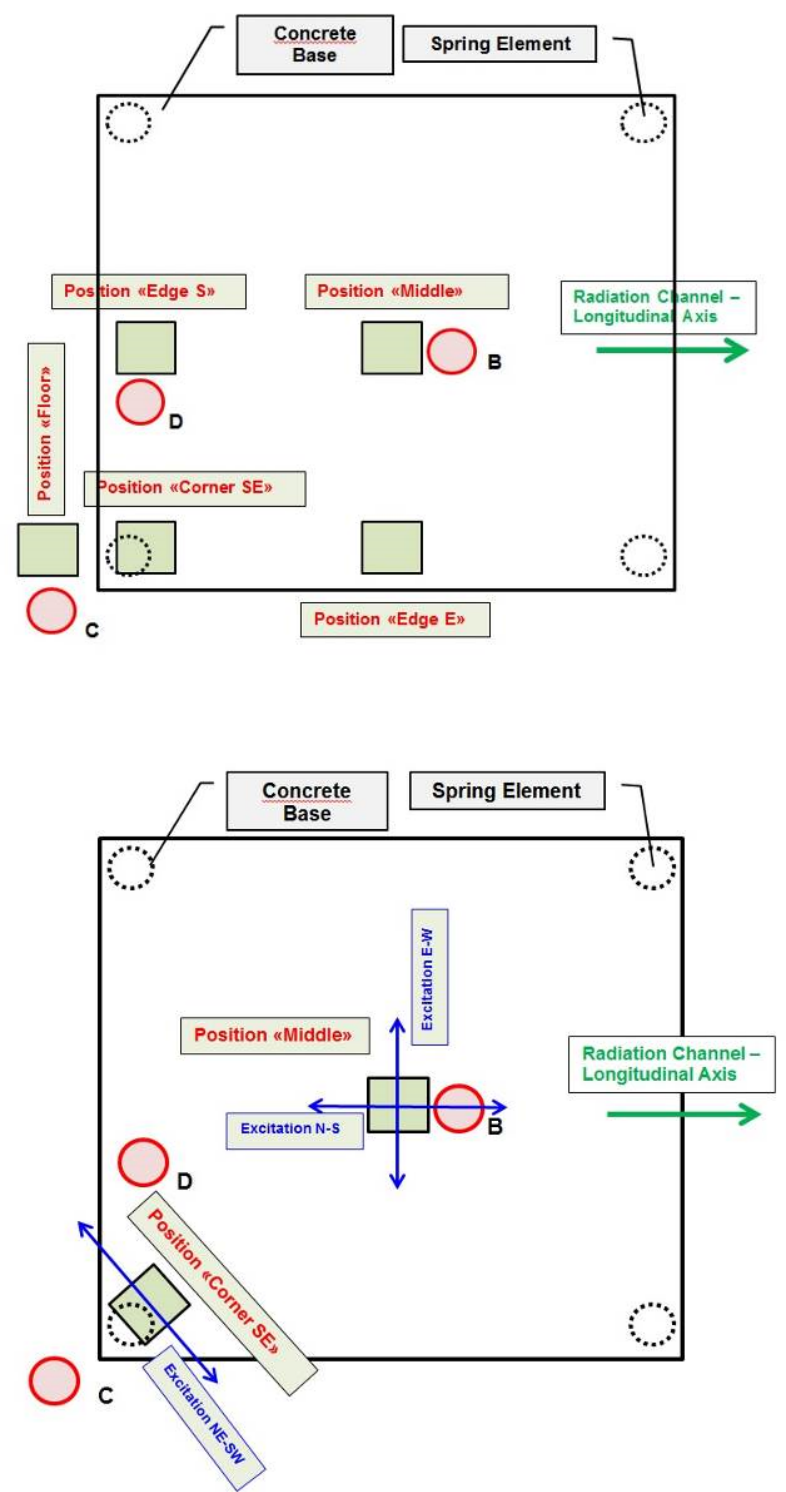

\section{Shaker positions}

\section{Triaxial sensor positions}

Uniaxial sensors (for the transfer spectrum):

Sensor X: on the shaker

Sensor Y: right next to the Shaker

Sensor Z: on the floor next to «Edge $\mathrm{S}$ »

Figure 13. Location of the shaker and the sensors.

\subsection{Measurement Results}

Figure 14 plots the transfer spectrum results. Figures 1518 plot triaxial sensor (vertical and horizontal excitation) representative results.
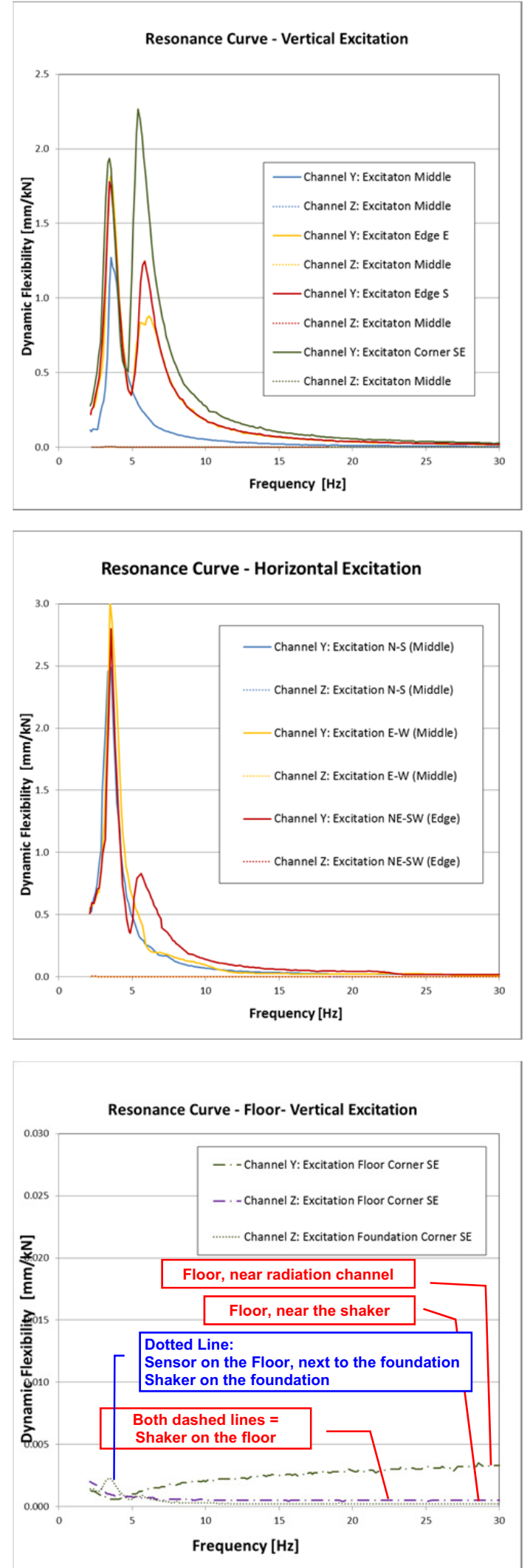

Figure 14. Transfer functions. 


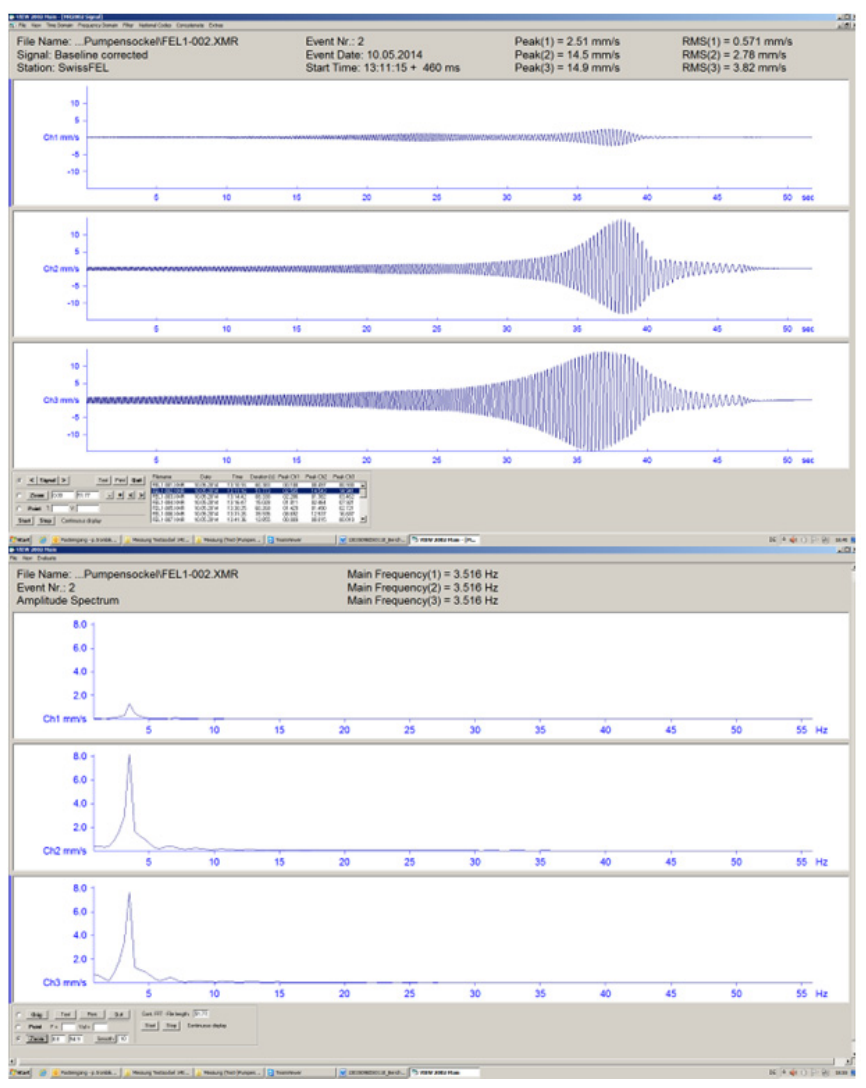

Figure 15. Measurement 002 - Shaker position «Edge S»/ Sensor position «B» (Vertical Excitation)

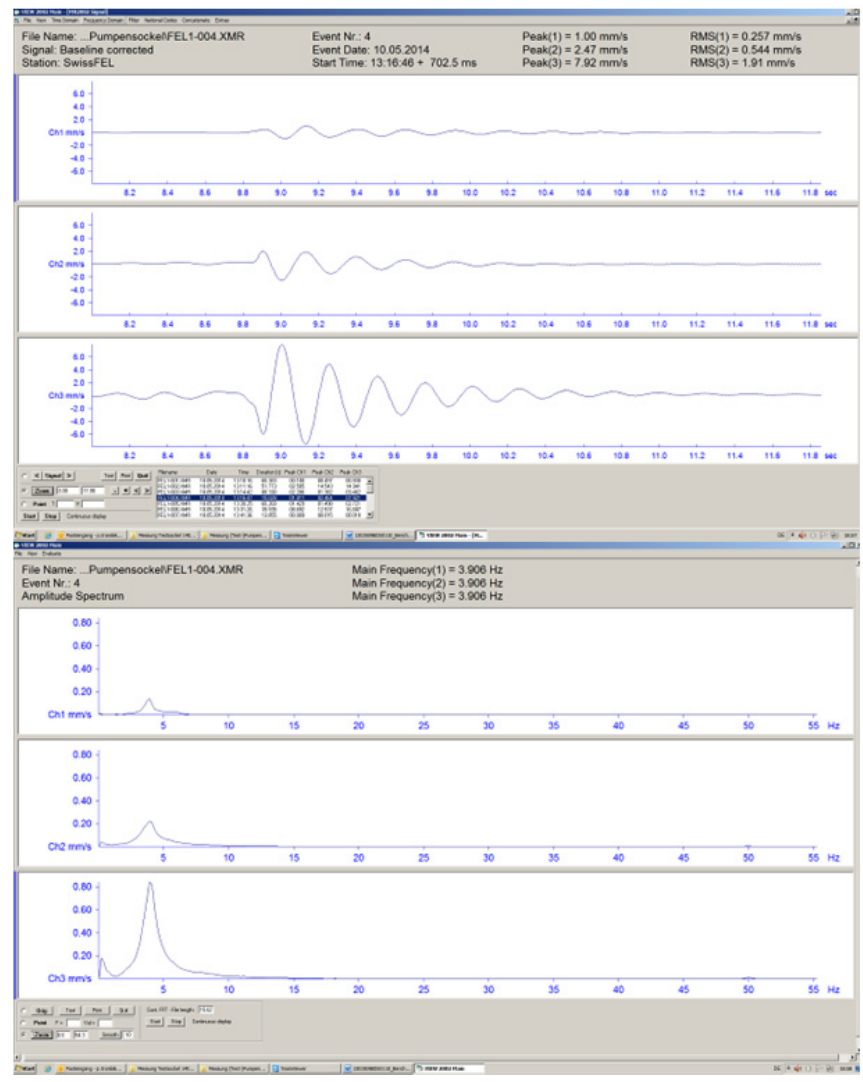

Figure 16. Measurement 004 - Jump on the foundation center «Edge S» / Sensor position «B»

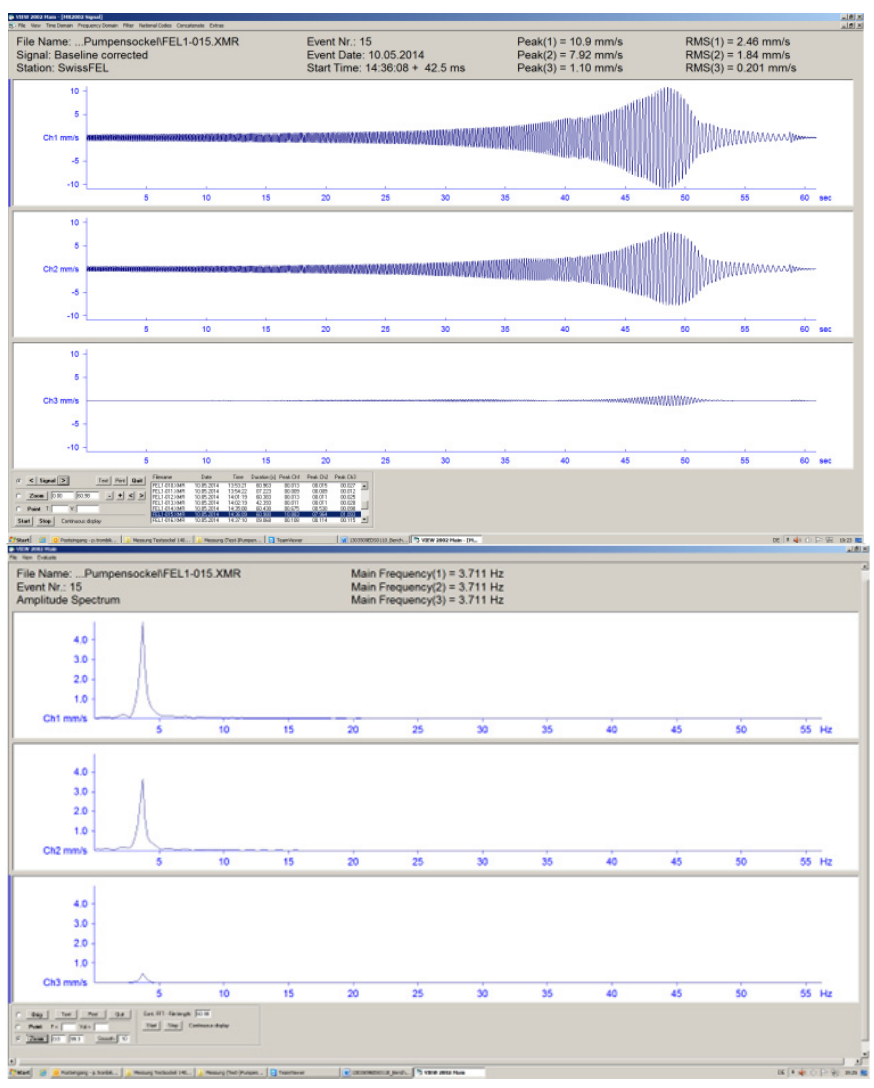

Figure 17. Measurement 015 - Shaker position «Corner SE» / Sensor position «B» (Horizontal Excitation)

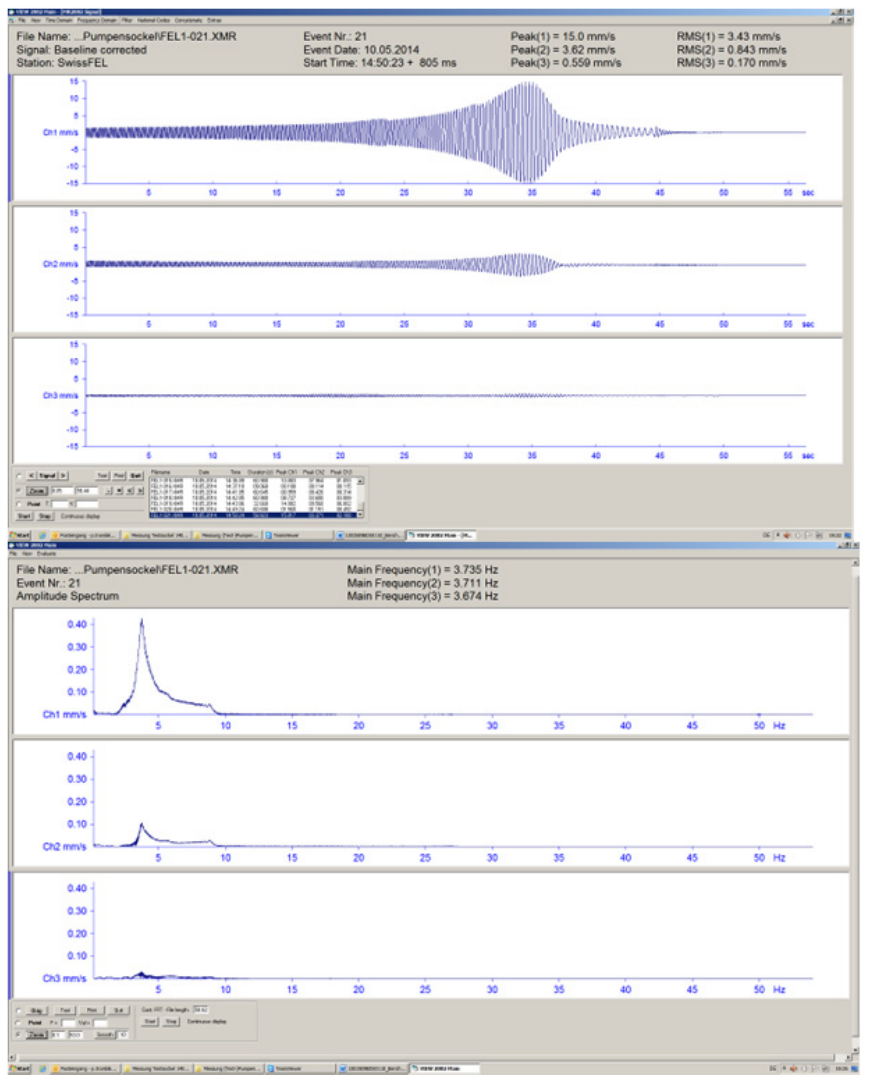

Figure 18. Measurement 021 - Shaker position «Middle» / Sensor position «B» $($ Horizontal Excitation $-\mathrm{N}-\mathrm{S})$ 


\subsection{Conclusions}

1) Eigenfrequencies

\begin{tabular}{|c|c|c|c|}
\hline $\begin{array}{l}\text { Measurem } \\
\text { ent No. }\end{array}$ & $\begin{array}{c}\text { Shaker } \\
(\mathrm{Hz})\end{array}$ & $\begin{array}{c}\text { Triaxial } \\
\text { sensor } \\
(\mathrm{Hz})\end{array}$ & $\begin{array}{l}\text { Corresponding } \\
\text { FE model mode } \\
(\mathrm{Hz})\end{array}$ \\
\hline \multicolumn{4}{|l|}{ Vert. Exc. } \\
\hline 002 & & 3.516 & Mode $01 / 3.60$ \\
\hline 004 & & 3.906 & Mode $03 / 3.94$ \\
\hline \multirow[t]{6}{*}{006} & & 3.516 & Mode 02 / 3.60 \\
\hline & 3.45 & & Mode 03 / 3.94 \\
\hline & 3.55 & & Mode 03 / 3.94 \\
\hline & 3.57 & & Mode 03 / 3.94 \\
\hline & 5.41 & & Mode $05 / 5.52$ \\
\hline & 5.85 & & Mode 06 / 5.60 \\
\hline \multicolumn{4}{|l|}{ Hor. Exc. } \\
\hline 015 & & 3.711 & Mode $01 / 3.60$ \\
\hline $018 / 019$ & & 3.711 & Mode 02 / 3.60 \\
\hline 021 & & 3.735 & Mode $01 / 3.60$ \\
\hline \multirow[t]{5}{*}{103} & & 3.516 & Mode 02 / 3.60 \\
\hline & 3.46 & & Mode $01 / 3.60$ \\
\hline & 3.49 & & Mode $02 / 3.60$ \\
\hline & 3.56 & & Mode 02 / 3.60 \\
\hline & 5.59 & & Mode 04 / 5.11 \\
\hline
\end{tabular}

The dynamic behavior of the system is favorable. The important first eigenmodes have a very low frequency. The FEM calculations are close to the measured properties.

2) The transfer spectra show that for the pump minimum operational frequency (1400rpm) the isolation factor is $97 \%$. For the maximum operational frequency (2980rpm) the isolation factor is $99 \%$. These values are excellent.

3) Figure 19 shows the measurements on the shaker (Ch1, acceleration), the concrete base (Ch2, velocity) and the floor (Ch3, velocity) for an increasing amplitude excitation. It can be seen that the ground vibration caused by the shaker is covered by the ambient noise. Therefore, a transfer function «Shaker Force» $\rightarrow$ «Ground Velocity» cannot be determined. By getting the maximum of the ground velocity one can determine a lower bound of the isolation factor: $1-0.024 / 9.64=99.75 \%$

4) Based on the unbalanced load of the pump, it is expected that the load that the shaker generates $(200 \mathrm{~N}$ at $50 \mathrm{~Hz})$ covers the expected pump force $(153 \mathrm{~N})$. It could be exceeded only if both pumps synchronize and run in phase.

5) In order to determine the transfer function between Floors 1 and 0 , the shaker was positioned vertically on the floor of Floor 1. Sensor Y (Ch2) was placed next to the shaker and sensor $\mathrm{Z}(\mathrm{Ch} 3)$ was placed on the floor of Floor 0. Moreover 3 jumps were done as an extra excitation. The results are shown in Figure 20. Again the vibration due to the shaker is covered by the ambient noise. Based on the maximum values that correspond to the jumps, the transfer function is on the order of $6 \%$

Based on the above it is concluded that the pumps will not create any vibration that would be larger than the ambient noise. Therefore the vibration limits set from the PSI are fulfilled.

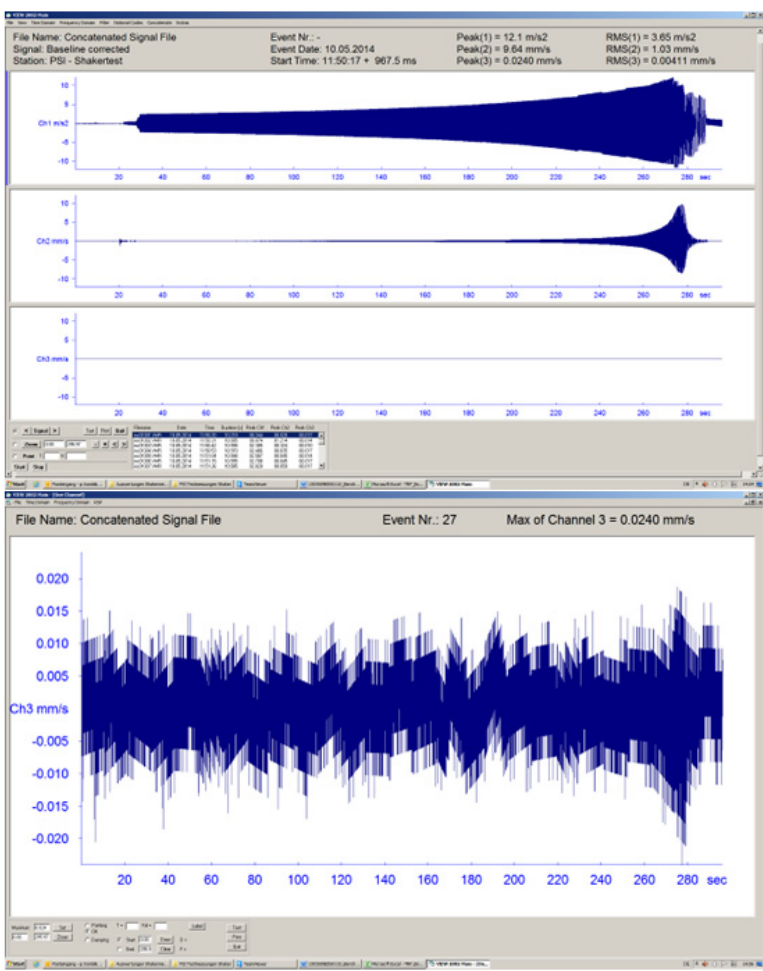

Figure 19. Tests to measure the «Shaker Force» $\rightarrow$ «Ground Velocity» transfer function (top); Ch3 zoom-in (bottom)

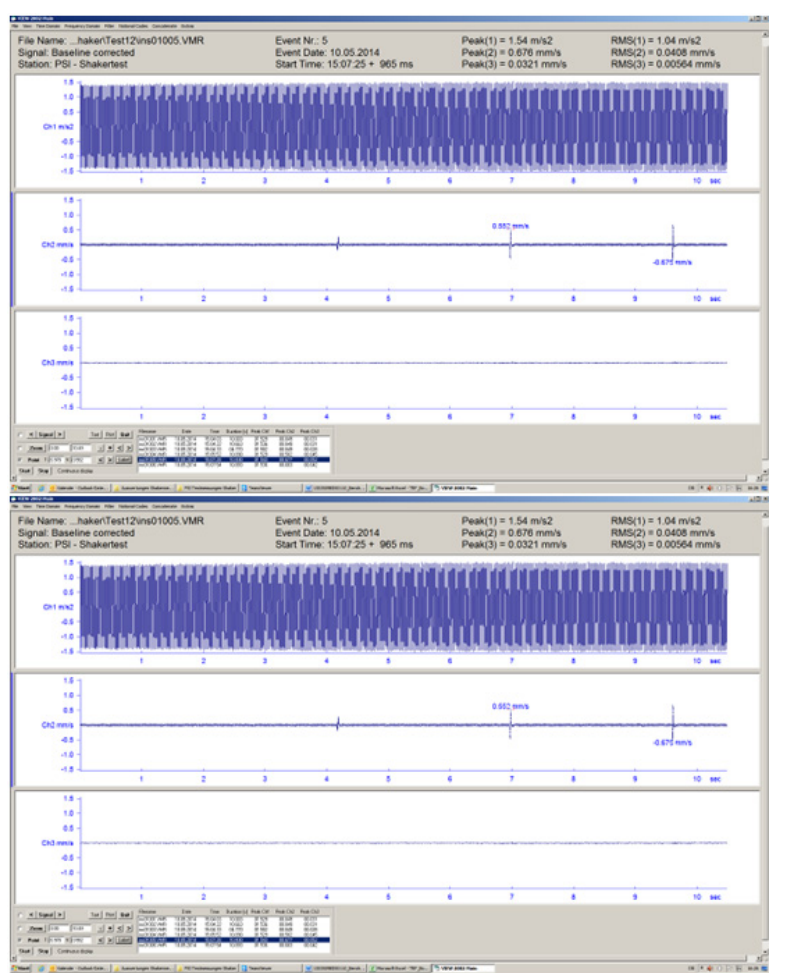

Figure 20. Tests to measure the «Floor $1 » \rightarrow\langle$ Floor $2 »$ transfer function (top); Ch3 zoom-in (bottom)

\section{References}

1. www.psi.ch (accessed on 2.6.2015)

2. Gartenmann Engineering AG, PSI SwissFEL Lösungen im Projekt bezüglich Schwingungsiolierungen (2012)

3. Gartenmann Engineering AG, PSI SwissFEL Systemvorgaben Schwingungen (2012) 